Linguagem em (Dis)curso - LemD, v. 8, n. 3, p. 613-640, set./dez. 2008

\title{
A LEITURA DE LIVROS DIDÁTICOS: UMA SITUAÇÃO NEGLIGENCIADA
}

\author{
Stella Maris Bortoni-Ricardo*
}

\begin{abstract}
Resumo: A leitura com compreensão é um problema crucial nas escolas brasileiras. Desde 1985, o Governo Federal adotou uma política de distribuição de livros didáticos a todos os alunos de escolas públicas. Esses livros são publicados por editoras particulares, mas sua seleção segue um cuidadoso processo no âmbito do Ministério da Educação. No entanto, pouca atenção tem sido conferida à compreensão desses livros pelos alunos a quem eles se destinam. Espera-se que qualquer dificuldade em sua compreensão seja sanada pelos professores em sala de aula. Nossa pesquisa recente tem mostrado que de fato os alunos têm muita dificuldade na compreensão dos seus livros didáticos. Este ensaio focaliza estratégias de andaime que professores podem adotar para facilitar para os alunos a leitura com mais proficiência de seus livros didáticos.
\end{abstract}

Palavras-chave: compreensão leitora; livro didático; estratégia de leitura; estratégia de andaime.

\section{INTRODUÇÃO}

Tomo emprestado de Erving Goffman (2002) a segunda parte do título deste artigo. No nosso caso, a situação negligenciada é a compreensão do texto dos livros didáticos pelos estudantes a quem eles se destinam.

O primeiro órgão criado no Brasil para legislar sobre políticas do livro didático, o Instituto Nacional do Livro, data de 1929. E a primeira legislação sobre o livro didático, propriamente dita, é o Decreto-Lei $\mathrm{n}^{\circ}$ 1006 de 30 de dezembro de 1938, que institui a Comissão Nacional do

* Professora da Universidade de Brasília (UnB). Doutora em Lingǘstica.. E-mail: <stellamb@terra.com.br>. 


\section{4}

Livro Didático - CNLD. Em outubro de 1967, a Lei no 5327 criou a Fundação Nacional do Material Escolar - FENAME - a quem cabia a produção e distribuição do material didático. Essas tarefas foram assumidas em 1971 pelo Instituto Nacional do Livro - INL.

Desde 1985, foi instituído o Programa Nacional do Livro Didático - PNLD - por meio do qual o MEC passou a adquirir e distribuir livros didáticos de Alfabetização, História e Geografia, Língua Portuguesa, Matemática, Ciências e Estudos Sociais para o Ensino Fundamental. Em 2003, a distribuição incluiu também o Ensino Médio, em um volume único para o Norte e Nordeste. Três anos depois, começou a ser atendido o Ensino Médio nas outras regiões. A partir de 1993, o MEC passou a constituir comissões formadas por professores e especialistas para avaliar a qualidade dos livros e elaborar um guia de livros didáticos. Essa tarefa é atribuída a diversas universidades por disciplinas (COELHO, 2007). O programa brasileiro de livros didáticos é o terceiro maior do mundo, só fica atrás dos programas da China e dos Estados Unidos e atende a 36,6 milhões de alunos da rede pública de ensino. Segundo a Câmara Brasileira do Livro e o Sindicato Nacional dos Editores do Livro, mais da metade dos 310 milhões de exemplares vendidos no Brasil no ano passado eram livros didáticos (cf. BORTONIRICARDO, 2008).

O PNLD representa um avanço relevante na política educacional brasileira. No entanto, o esforço e o cuidado que tem o Ministério da Educação para produzir e distribuir os livros didáticos em todo o país não tem como contraparte um acompanhamento na trajetória dos livros até a sala de aula, para que se possa avaliar como se realiza essa leitura. Duas questões se impõem: será que os alunos compreendem sem maiores dificuldades os textos de seus livros didáticos? Se isso não acontece, será que os professores atuam como agentes letradores, mediando o processo de leitura para que esse seja produtivo?

O PNLD é um programa de política educacional e lingüística de grandes dimensões. Por isso mesmo, se ficar constatado que os nossos alunos têm muita dificuldade de ler com compreensão o texto dos livros didáticos distribuídos às escolas, vamos concluir que todo o esforço econômico da sociedade brasileira para prover livros às escolas fica prejudicado e pode ser até em vão. 
No mundo corporativo, existe uma constante preocupação em se desenvolver uma logística que assegure a compreensão dos textos produzidos ou divulgados no âmbito das empresas, tanto em relação à comunicação interna, com filiais ou franqueados, quanto à comunicação com o público consumidor. Tornar textos publicitários compreensíveis e de agradável leitura é uma das principais preocupações dos profissionais dessa área. No caso dos livros didáticos, isso não ocorre.

O Ministério da Educação e as secretarias estaduais e municipais, responsáveis pela produção do material didático, aparentemente, só se preocupam com a fase da elaboração. Não se detêm numa logística de acompanhamento que avalie a recepção dos textos pelos leitores. Tomam como tácito que o texto será compreendido pelo estudante e, se não o for, o professor se encarregará de fazer a mediação pedagógica ajudando no processo de compreensão de seus alunos.

\section{DISCUSSÃO}

Pereira (2007), pesquisando aulas de Geografia e de Filosofia em uma escola de Ensino Médio no Distrito Federal, constatou que a maioria dos professores não desenvolvia estratégias pedagógicas que pudessem facilitar a compreensão do texto. Embora não se posssa generalizar os resultados de uma pesquisa qualitativa, desenvolvida no microcosmo de uma escola, sabemos, por depoimentos de professores, alunos e gestores educacionais, que nossos alunos têm problemas na leitura produtiva dos livros didáticos. Usando uma linguagem bem prosaica, podemos dizer que, em alguns casos, o professor indica a lição a ser lida e, a partir daí, "o aluno que se vire".

Como discutiremos brevemente na seqüência deste trabalho, a compreensão da leitura é um processo complexo, influenciado por muitas variáveis, mas parece existir um consenso entre os pesquisadores quanto ao papel proeminente dos conhecimentos prévios dos leitores na viabilização de uma leitura com compreensão.

Ora, o conhecimento prévio - conhecimento de mundo ou enciclopédico - que nossos estudantes detêm pode estar muito distante dos conteúdos dos textos didáticos, quase sempre muito pautados em 


\section{6}

textos acadêmicos. Por exemplo, em um texto didático de sétimo ano foi incluída uma crônica de Fernando Sabino sobre suas experiências como locutor de rádio. $O$ texto não é vazado em linguagem erudita ou muito distante da realidade dos leitores potenciais. Mas o autor faz referência à BBC, ao sepultamento do cantor Francisco Alves e ao Big Ben. Todos esses itens eram completamente estranhos à experiência de vida do jovem aluno de sétima série. A professora que acompanhava a sua leitura teve de tecer longas explicações para que não ficassem "buracos" na compreensão que o leitor se esforçava por construir. No caso do Big Ben, ele estabeleceu uma associação com o "big bang" de que já ouvira falar, o que deu ensejo a um novo round de explicação por parte da professora. De fato, para ler com entendimento, a crônica considerada um exemplar de leitura acessível, o jovem necessitava de um ou mais interlocutores, mais experientes na cultura letrada para ajudá-lo. Sem esse apoio, sua leitura ficava prejudicada.

Essa habilidade de escrever de maneira simples, de que temos modelos antológicos como o "Dom Quixote das crianças" de Monteiro Lobato, não compromete o conteúdo do texto. Um livro didático pode ser preciso, informativo, atualizado quanto ao estado da arte da disciplina, sem ser opaco, de difícil leitura.

É preciso que se tenha bem clara a especificidade dos diversos gêneros empregados na descrição e divulgação da pesquisa científica, que vão variar em função do público a que se destinam. Os textos escritos pelos cientistas e publicados nas revistas especializadas, que serão lidas pelos seus pares, diferem dos relatórios de divulgação científica, destinados ao público em geral. Zamboni (2001) faz uma clara distinção entre o texto científico essencial à ciência e o texto de divulgação científica, necessário ao público leigo. Esses últimos estão mais próximos dos livros didáticos, tanto em relação aos seus objetivos, quanto em relação ao seu público leitor. No entanto, há textos de manuais escolares em que se podem encontrar construções textuais eivadas de um jargão que é mais pertinente e adequado aos textos científicos.

Sousa (2001) discute a transformação de gêneros científicos em gêneros para uso pedagógico, que ela denomina mediacionais, pois são interativos e envolventes e atendem a expectativas comunicativas em um contexto específico de letramento, que é a educação a distância. Muitas das estratégias lingüístico-textuais que a autora analisa para o gênero 
mediacional podem aplicar-se também aos livros didáticos que não sejam destinados à educação a distância.

Considerando as dificuldades causadas por textos escolares opacos, temos de levar em conta principalmente que podem faltar ao estudante outros interlocutores, além do professor, na sua rede de relações sociais, com quem possa discutir ou comentar o conteúdo de suas leituras escolares obrigatórias. Imagina-se que essa situação seja muito comum, se levarmos em conta os dados do INAF - Índice Nacional de Alfabetismo - (acessíveis em www.ipm.org.br), segundo os quais cerca de dois terços dos adultos brasileiros são analfabetos funcionais.

Dados que temos coletado no âmbito do Projeto Letramento no Ensino Fundamental (LEF), por meio de protocolos de leitura produzidos com um pequeno grupo de alunos do sexto e sétimo anos, demonstram que esses alunos têm grande dificuldade na compreensão dos textos de seus livros didáticos.

Durante as sessões de leitura, conduzidas com cada aluno individualmente, a pesquisadora desenvolve estratégias para facilitar a compreensão do texto; em outras palavras, constrói andaimes, faz uma mediação de modo a tornar o texto lido mais compreensível. Andaime é um termo metafórico, introduzido por Bruner (1983), que se refere à assistência visível ou audível que um membro mais experiente de uma cultura presta a um aprendiz, em qualquer ambiente social, ainda que o termo seja mais empregado no âmbito do discurso de sala de aula. Dois conceitos básicos subjacentes à noção de andaime são a zona de desenvolvimento proximal (ZDP) de Lev Vygotsky, retomado por Jerome Bruner, e as pistas de contextualização, como propostas por John Gumperz, principal teórico da Sociolingüística Interacional (BORTONIRICARDO; SOUSA, 2006).

Conforme se pode ler em http://www.leadertalk.org/2007/10/ interesting-res.html, os leitores, maduros ou iniciantes, associam as informações do texto a suas próprias experiências e vocabulário, de modo a construir sentidos sobre o que estão lendo. Muito relevante também no processo é a sua experiência anterior de leitura (KLEIMAN; MORAES, 1999). Ted Hasselbring, professor de educação especial no Peabody College em Vanderbilt, faz menção a dois tipos de problemas 


\section{8}

de leitura: de codificação, que envolve habilidades de nível baixo; e de incompreensão dos textos, que se relaciona a habilidades de alto nível. $\mathrm{E}$ completa: quanto mais hábeis com as primeiras, mais memória operacional os leitores liberam para o segundo tipo de habilidades. Ao final, enfatiza a importância do conhecimento anterior (background knowledge) no processo da leitura (ver também a esse respeito: KLEIMAN, 1997). Em publicação do PIRLS: Marcos Teóricos y especificaciones de avaluación (2006, p. 15), Mullis, Kennedy, Martin e Sainsbury, pesquisadores responsáveis pelo documento, ressaltam que.

quando os leitores interpretam e integram idéias e informação a partir do texto, com freqüência necessitam fazer uso de sua compreensão do mundo, estabelecendo conexões que podem ser implícitas ou podem estar abertas a interpretações baseadas em sua própria perspectiva. Ao interpretar e integrar idéias e informação do texto, é possível que tenham que fazer uso de seus conhecimentos e experiências anteriores. (traduzido do espanhol)

Com relação à importância desse conhecimento anterior, ou conhecimento de mundo, achamos importante atentar para o conhecimento do vocabulário, sem negligenciar, contudo, as muitas outras variáveis que têm papel relevante na complexa questão da compreensão na leitura.

Os lingüistas, desde os estágios formativos da disciplina, sabem que "o léxico da língua é o componente que mais nitidamente reflete o ambiente físico e social dos falantes" (SAPIR, 1969, p. 45). O conhecimento que os falantes têm desse ambiente físico e social é processado na forma de estruturas de dados ou frames (molduras). Uma moldura, de acordo com Brown e Yule (1983), é uma dada representação do mundo fixada em nossa mente. A compreensão do que lemos ou ouvimos implica confrontar as informações que estamos adquirindo com essas estruturas mentais de dados. Se um item ou mais do vocabulário que compõe um texto não se encaixar em uma moldura armazenada na mente, a compreensão do enunciado ou do texto fica necessariamente prejudicada (BORTONI-RICARDO, 2007).

Marcuschi (2008, p. 252) chama a atenção para a complexidade do processo de compreensão da leitura, demonstrando como o leitor trabalha inferencialmente com informações textuais, conhecimentos 
pessoais e suposições. Segundo o autor, "as inferências são produzidas com o aporte de elementos sociossemânticos, cognitivos, situacionais, históricos e lingüísticos de vários tipos que operam integradamente. Para ele, compreender é essencialmente uma atividade de relacionar conhecimentos, experiências e ações num movimento interativo e negociado. O autor ainda se vale da metáfora de Dascal (1981), que imagina o texto como uma cebola cujas camadas internas representam as informações objetivas, um núcleo informacional que consiste em 30\% a $50 \%$ do que entendemos no texto. Envolvendo esse núcleo está uma camada intermediária que é passível de interpretações diversas, porém válidas, justamente o espaço das inferências. Em certos textos, essa camada representa 50\% no processo de compreensão. A camada superficial externa, mais sujeita a equívocos, é o domínio de nossas crenças e valores pessoais. Aí se acomodam as extrapolações.

Todo esse processo é profundamente influenciado pelo conhecimento de mundo que o leitor traz consigo para promover o diálogo com o texto no esforço para realizar uma leitura produtiva.

Para ilustrar as dificuldades que estudantes do Ensino Fundamental enfrentam para construírem sentidos a partir do texto didático que têm de ler e de onde têm de assimilar informações para desenvolver seu trabalho escolar, reproduziremos aqui trechos de dois protocolos de leitura, que são parte da pesquisa já referida, que foram gravados e transcritos. O colaborador nesse estudo é um aluno de 15 anos que está cursando a $7^{\text {a }}$ série. Como se trata de um estudo longitudinal, com duração prevista de dois anos, iniciado em 2007, esse aluno já produziu diversos protocolos da leitura de seu livro de História do Brasil (BORTONI-RICARDO, 2008; www.stellabortoni.com.br). Nos fragmentos da sessão que vamos comentar, a professora pesquisadora $(\mathrm{P})$ e o sujeito colaborador (SC) estão lendo em conjunto um texto de Ciências, do "Jornal do Aluno", distribuído pela Secretaria de Educação local. Esse material foi elaborado por consultores das diversas áreas de conhecimento para a Secretaria de Educação de São Paulo, que o cedeu à Secretaria de Educação do DF, e foi utilizado, durante um período, por alunos que estão matriculados na correção de fluxo escolar, isto é, acompanham aulas de aceleração com o objetivo de se corrigir a defasagem entre idade e série. 
As seqüências lidas pelos dois interagentes estão entre aspas; seqüências omitidas da gravação original estão indicadas com /.../. É importante observar que o texto lido nesses eventos não é tão opaco como outros que fazem parte do kit de livros do mesmo estudante, distribuído pelo Ministério da Educação. No referido "Jornal do Aluno" já se observa um razoável esforço dos autores no sentido de facilitar a comunicação com os educandos.

1. P - Agora nós vamos ver rapidamente o que você vai ver de ciências nesse próximo mês, vamos lá.

2. SC - "Nutrição e saúde. Com seus professores de ciências, você e seus colegas vão trabalhar com assuntos relacionados com a ciência e a saúde. Entre eles, a presença de aditivos nos alimentos e os riscos que podem oferecer à saúde."

3. P - Então vamos ver aqui. Qual vai ser o tema das suas aulas de ciências. Que que é...?

A P inicia por induzir o SC à identificação do tema, que ele poderia ter inferido pela leitura do subtítulo em (2) e também pela apresentação (2) que os autores promovem dirigindo-se diretamente ao aluno ("você e seus colegas vão trabalhar..."). O SC, no entanto, não processa a compreensão da palavra "tema", que a $\mathrm{P}$ usou e atende à solicitação dela prosseguindo a leitura (4).

4. SC - "Elaborar..."

5. P - Antes de lermos isso só me responde. Qual vai ser o tema? Vocês vão estudar sobre o quê?

Só então a P percebe que 'tema' é um item lexical problemático e elabora uma paráfrase (5). O SC então fornece a resposta correta (6).

6. SC - Sobre a saúde e os alimentos.

7. P - Nutrição quer dizer?

A P antecipa que a palavra "nutrição" pode ser desconhecida, mas pela resposta de SC (8), vê-se que esse item lexical está presente pelo menos em seu vocabulário passivo, de recepção.

8. SC - Alimentos que a gente come. 
9. P - Muito bem, a alimentação que a gente come é nossa nutrição. $\mathrm{O}$ ar que a gente respira também nos alimenta, é um nutriente, mas aqui vão ser os alimentos mesmo. Eles vão... vocês vão trabalhar a presença de quê?

10. SC - "Aditivos nos alimentos e os riscos que podem oferecer à saúde".

O SC localiza no texto a informação que precisa repassar à sua interlocutora. No entanto, ele não sabe o que são aditivos, naquele contexto, como se vê na troca de turnos (11) e (12).

11. P - Você já sabe o que são aditivos?

12. SC - Não.

13. P - Você não sabe o que são aditivos, você ainda vai aprender este mês. Mas leia aqui "a presença..."

A P opta por levá-lo a realizar uma inferência a partir da leitura dos períodos subseqüentes.

14. SC - “... A presença de aditivos, os alimentos e os riscos que podem oferecer à saúde.”

15. P - Então, os aditivos, que... que os aditivos podem fazer para nós?

16. SC - Muito mal à saúde.

O SC de fato consegue processar a inferência corretamente. Há algumas sessões a palavra "riscos" havia sido discutida por eles. A P ratifica a contribuição de SC em (16).

17. P - Podem fazer mal à saúde. Riscos são?

18. SC - Perigos.

19. P - Riscos são perigos. Riscos são problemas. Então, você vai estudar em ciências os aditivos nos alimentos e esses problemas, esses riscos. Então, será que aditivos são uma coisa boa ou ruim?

20. SC - Ruim.

21. P - Que será que são esses aditivos que tem nos nossos alimentos?

22. SC - Eu acho que a gordura. 
23. P - A gordura não é um aditivo. Aditivo é uma coisa que se coloca no alimento, se acrescenta no alimento. A gordura já é parte do próprio alimento. Aditivos que fazem mal à saúde e que estão sendo colocados nos alimentos... são venenos... pra quê?

24. SC - Para...

O SC hesita.

25. P - Esses venenos têm o nome de agrotóxicos. Já ouviu falar?

A $\mathrm{P}$ neste turno associou os aditivos apenas aos resíduos de agrotóxicos. Com o prosseguimento da leitura, ela própria tem um melhor entendimento do conceito de aditivos.

26. SC - Ah, já.

27. P - Então, esses agrotóxicos são postos nas plantas pra quê?

28. SC - Pra não causar muitas lagartas.

29. P - Isso mesmo. Ótimo. Para que os insetos não comam a planta. Vamos pensar num pé de tomate. Você já viu um pé de tomate?

Uma estratégia muito comum que a $\mathrm{P}$ usa repetidas vezes durante a interação é relacionar a informação lida com a vida cotidiana do SC.

30. SC - Já.

31. P - Sua casa tem?

32. SC - Tinha, só que o cachorro arrancou.

33. P - O cachorro estragou?

34. SC - Aham.

35. P - Muito bem, como era só um pezinho de tomate não tinha perigo de dar ali pragas e acabar com o pé de tomate. Mas se você pensar em uma fazenda com muitos pés de tomate, tomateiros, ali pode dar uma praga e comer os pés de tomate. Por que que os agricultores põem diversos agrotóxicos nas plantações?

36. SC - Pra matar os insetos que chegam. 
37. P - Para matar os insetos. "Agro" é um pedacinho de palavra que você vai encontrar na palavra 'agricultura', tem a ver com essa produção agrícola.

E tóxico, que... que é tóxico?

A $\mathrm{P}$ recorre a uma informação lingüística, de natureza morfológica em (37).

38. SC - Tóxico é uma coisa que... toxina...

39. P - Que tem toxinas porque intoxicam. São ve?

40. SC - nenos.

41. P - São venenos. Às vezes esse veneno, muitas vezes, quase sempre, os venenos que os agricultores põem nas plantações para proteger as plantações dos insetos, esses venenos podem ser tóxicos também, podem fazer mal à?

42. SC - Aos tomates, às plantações.

43. P - Faz mal às plantações e faz mal...

44. SC - À gente também.

A P trabalha com o SC no nível inferencial. Em (42) o SC não realiza completamente a inferência, mas com o apoio de mais um andaime em (43), ele é bem sucedido.

45. P - À gente também. Então quando eles estão dizendo que a gente vai estudar...

A P indica o título do trabalho

46. SC - "... aditivos, os alimentos e os riscos que podem oferecer à saúde."

47. P - Então você já sabe que você vai estudar sobre o quê?

48. SC - Os aditivos, que eles põem nos alimentos.

49. P - Nas plantas. E qual o nome que nós damos a esses aditivos?

50. SC - Agrotóxicos.

51. P - Então o que que você vai estudar? Você vai estudar aditivos, alguns aditivos são agrotóxicos, mas há outros aditivos. 
Que são postos para que as plantas cresçam mais, para que os frutos fiquem maiores, certo? Mas você vai ver que esses aditivos, que... que eles fazem?

52. SC - Põem em risco a nossa saúde.

53. P - Põem em risco a nossa saúde. Então veja que o primeiro exercício que você vai fazer... nós não vamos fazer hoje porque não temos tempo, mas leia aqui.

A P ratifica o turno do SC.

54. SC - "Você, seus colegas e seu professor vão construir juntos a tabela a seguir com informações sobre os nutrientes e as principais funções que elas desempenham no nosso corpo. Você também vai propor um título para essa tabela. Como você sabe a tabela também é uma forma de registrar informações e o título deve expressar aquilo que ela contém."

55. P - Então o que... que vocês vão fazer nessa grande tabela? Vocês vão... primeiro, nós já sabemos que vocês vão estudar aditivos e os riscos. Além disso, eles estão pedindo que você faça o quê? Você e seus colegas coloquem aqui "Os alimentos e os nutrientes". Que que são nutrientes?

56. SC - São... acho que as vitaminas.

57. P - São as vitaminas, são aquelas propriedades que os alimentos têm. Vamos olhar um [alimento] pra gente ver como é que a gente vai fazer isso, pra gente aprender. Tem muita coisa pra você me ensinar da próxima vez, hein?

A $\mathrm{P}$ aceita a resposta parcial, mas a expande, com a finalidade de levar o SC a uma reconceptualização (cf. CAZDEN, 1988).

58. SC - É.

59. P - Aqui, primeiro é o?

60. SC - Tomate.

61. P - Quais são os nutrientes que o tomate tem?

62. SC - "Tem proteínas, amido, alguns sais minerais, vitaminas A, B e C, água e é rico em...”

63. $\mathrm{P}-$ Aqui eles repetem. 
A P mostra ao SC que as informações estão sistematizadas em um quadro sinótico e as reitera em (64), trabalhando a estratégia de recuperação de informações e valendo-se do quadro que consolida as informações do texto. Nos turnos seguintes P e SC passam a ler e buscar as informações no referido quadro incluído no capítulo. É uma experiência relativamente nova para SC, que não está familiarizado com esse tipo de texto não-contínuo que sistematiza informações anteriormente apresentadas.

64. Então, ele é rico em amido, vitamina A, B e C. Você se lembra daquela doença que dava nos marinheiros por causa que eles não comiam nada que tivesse vitamina $C$ ?

A P ativa a memória do SC que havia lido recentemente um texto sobre as navegações portuguesas nos séculos XV e XVI.

65. SC - É o escorbuto.

66. P - Escorbuto. A doença que dava nos marinheiros. Que... que eles não comiam, por exemplo?

A P está avaliando a informação recém-adquirida. É uma estratégia de avaliação formativa porque reforça o aprendizado. Como observa Villas-Boas (2002), nesse tipo de avaliação, em que os alunos exercem papel central, promove-se aprendizagem e se obtêm informações diagnósticas.

67. SC - Tomate.

68. P - Tomate. Qual uma fruta que você sabe que tem bastante vitamina $\mathrm{C}$ ?

69. SC - Vitamina C...

70. P - Laranja. Laranja e limão. Então vamos ver aqui... o que ... que você e seus colegas... Por que aí você vai ajudar os seus colegas a fazerem as tabelas. Nós já sabemos que o tomate tem proteínas, tem amido e tem sais minerais e vitaminas A, B e C e ainda tem bastante água, né? Então tudo isso, veja como o tomate é rico. Agora, se ele estiver cheio de aditivos e agrotóxicos aí é perigoso, precisa lavar bem. Qual o outro alimento?

A P aponta o quadro sinótico.

71. SC - O pão. 
72. P - O pão. Você gosta de pão?

73. SC - Gosto.

74. P - Quais são os nutrientes do pão?

SC lê na célula correta do quadro a informação:

75. SC - "Proteína, gorduras, vitamina B, alguns sais minerais, água" e só.

76. P - Ele é rico em amido. Então esses são os nutrientes do pão. Qual outro?

A P indica um outro alimento no quadro

77. SC - O feijão.

78. P - Gosta de feijão?

79. SC - Gosto.

80. P - Quais são os nutrientes do feijão?

81. SC - "Proteínas, amido, vitamina B, alguns sais minerais e é rico em proteínas e em amido".

82. P - Por isso é que os médicos recomendam que a gente coma feijão. E entre os sais minerais que o feijão tem, tem o ferro, ferro é bom pra deixar a gente forte. E este aqui?

83. SC - Arroz

84. P - Arroz você come duas vezes por dia, não come?

85. SC - É.

86. P - E que... quais são os nutrientes do arroz?

87. SC - "Proteínas, amido, fibras, vitamina B, alguns sais minerais, água e ele é rico em amido".

88. P - Rico em amido. Igual pão, pão é rico em amido e o arroz também. Se você come um não precisa comer o outro. Agora vamos ver outra coisa que eu sei que você não gosta de comer.

89. SC - "Peixe."

90. P - Você gosta de comer?

91. SC - Não.

BORTONI-RICARDO - A leitura de livros didáticos... 
92. P - Eu gosto. Eu como três vezes por semana. Olha os peixes, que... que eles têm de nutrientes?

93. SC - "Proteínas, gorduras, sais e ferros, iodo, vitamina B e água".

94. P - Eles são tão... são ricos em?

95. SC - "Proteínas, vitamina B, sais e ferros e iodo".

96. P - Muito bem, veja, qual outro alimento aqui que também tem muita proteína?

97. SC - Tem muita proteína...

98. P - É, olha aqui, aqui no quadro... vamos ver nesses alimentos com que você vai trabalhar até aqui... que nós já vimos até aqui, quais são ricos em proteína?

A P está treinando com o SC a estratégia de localização de uma informação pontual no quadro.

99. SC - "A carne de boi"...

100. P - A carne de boi é rica em proteína. E o peixe é?

101. SC - "Rico em proteína".

102. P - Então quer dizer que se você comer peixe naquela refeição não precisa comer?

103. SC - Feijão... não.

104. P - Feijão também. Feijão também porque ele é rico em proteína. Mas outra coisa que você não precisa comer?

105. SC - Carne de boi.

Novamente a P está trabalhando com a capacidade inferencial do SC. Na sessão seguinte é retomado o trabalho com o texto de Ciências do mesmo Jornal do Aluno.

1. P-Vamos ver a... vamos ler então essa ficha 5 , que é de ciências. Vamos lá.

2. SC - "Leia o texto abaixo e a seguir responda à questão proposta, discutindo-a com seus colegas de grupo. E você já sabe, vocês conversam, trocam idéias, mas cada um anota em seu caderno as conclusões a que chegaram. Muitos estudos têm sido 
feitos no sentido de identificar os efeitos dos aditivos químicos na nossa saúde. Alguns estudiosos revelam ter verificado a ocorrência de dores de cabeça crônicas em trabalhadores de fábricas de aditivos em função da exposição contínua dessas pessoas àquelas substâncias. Dizem também que têm identificado em algumas pessoas desenvolvimento de urti... urticária...

O SC hesita diante de uma palavra desconhecida. A P esclarece.

3. P - Urticária. Sabe o que é urticária? Não? Urticária é uma doença que dá coceira, a gente começa a se coçar. Então essa doença é chamada urticária. Vambora, vamos à frente.

4. SC - "Dizem também terem identificado em algumas pessoas o desenvolvimento de urticária como resultado de uma reação alérgica a alguns aditivos como o corante tartrazino."

5. P - Tartrazino, que é isso? Corante tartrazino? Ele é um?

6. SC - Acho que é um tipo de corante.

7. P - Ele é um tipo de corante...

8. SC - Antialérgico. Acho que é isso... Não sei muito bem não...

9. P - Você não sabe muito bem. Nós estamos lendo sobre o quê?

10. SC - Ciências.

11. P - Ciências. Esse texto que nós estamos lendo sobre ciências está tratando de quê?

A P leva-o a recuperar o tema do texto.

12. SC - Das doenças que... dos efeitos dos aditivos químicos.

13. P - Então, nós vamos ler mais sobre aditivos químicos. $\mathrm{O}$ primeiro que você viu aqui como é que chama?

14. SC - Tartrazino.

15. P - Corante tartrazino. Vamos ler pra ver se nós vamos entender qual é o efeito... pra que que serve o corante tartrazino e qual o efeito dele. Vamos continuar.

16. SC - "Alguns aditivos, no entanto, já têm efeitos mais bem conhecidos sobre a saúde e eles não são animadores. A tabela 
abaixo apresenta algumas dessas substâncias e sua ação para predisposição para doença."

17. P - O que que é ação para predisposição para doença?

18. SC - É... eu acho que quando as pessoas...

19. P - Quando as pessoas?

20. SC - Facilitam a... a chegada das doenças.

21. P - Então, que que nós já temos em relação... que... que os pesquisadores estão nos dizendo em relação aos aditivos?

22. SC - Que a gente tem que ficar muito atentos às... aos alimentos que a gente compra.

23. P - Eles estão garantindo que todos os aditivos fazem mal?

24. SC - Não.

25. P - Que que eles estão dizendo?

26. SC - Que... quase todos... a maioria tem... aditivos químicos. /.../

SC continua a leitura:

27. SC - "E mais, para que usar algo que pode causar danos à saúde se há muitas outras formas de se consumir alimentos gostosos e saudáveis?”

28. P - Que que ele está dizendo? Que que o autor do livro está dizendo?

29. SC - Que... que a gente não... pode trocar alimentos que a gente... que causar danos à saúde e... pra trocar pelos alimentos saudáveis.

30. P - É. Se você pode comer alimentos saudáveis, por que que vai comer alimentos com aditivos químicos, né? E então?

31. SC - "Você mudaria alguma coisa em seus hábitos de consumir alimentos como salsicha e outros produtos embutidos, enlatados e doces industrializados? Justifique sua resposta."

32. P - Quais são os alimentos que eles estão dizendo que nós deveríamos, que vocês alunos, mas todos nós deveríamos evitar? Que tipos? 
33. SC - Salsicha...

34. P - A salsicha é um tipo de alimento?

35. SC - Embutidos.

36. P - Você conhece outros alimentos embutidos?

37. SC - Não sei, mas acho que ketchup.

38. P - Ketchup não é alimento embutido... ele é um alimento com muitos aditivos, mas ele não é embutido. Olha, exemplos de embutidos são lingüiça, presunto e salsichas. Então, que que ele estava... vamos ler de novo a pergunta que o autor faz a você.

39. SC - "Você mudaria alguma coisa em seus hábitos de consumir alimentos como salsicha e outros produtos embutidos, enlatados e doces industrializados? Justifique sua resposta."

40. P - Então, eles estão perguntando a você se você?

41. SC - Trocaria esses alimentos embutidos por...

42. P - Eles estão perguntando... vamos ler aqui de novo. "Você mudaria..."?

43. SC - "Você mudaria alguma coisa em seus hábitos de consumir alimentos como salsicha e outros produtos embutidos, enlatados e doces industrializados?"

44. P - Então eles estão perguntando se você mudaria o hábito de comer o quê?

45. SC - Salsicha...

46. P - Salsichas e outros?

47. SC - Embutidos.

48. P - Que mais?

49. SC - Enlatados.

50. P - Enlatados e?

51. SC - Doces industrializados.

52. P - Que tipo de enlatado a gente come?

53. SC - Sardinha./.../ 
54. P - Então, eles estão perguntando se você mudaria seus hábitos se você soubesse todos os problemas que os aditivos causam, se você mudaria. Mudaria ou não mudaria?

55. SC - Depende.

56. P - Depende de quê?

57. SC - Do que eu for trocar... Tipo assim...

58. P - Tá certo, depende do que você for trocar. O que por quem. Por exemplo, o que... que você estaria disposto a trocar e o que... que você não estaria disposto a trocar? Por exemplo, que embutido você estaria disposto a trocar?

59. SC - Ah... ah... salsicha.

60. P - Salsicha? Você trocaria salsicha pelo quê? Que... que queria no lugar da salsicha?

61. SC - Carne.

62. P - Carne é uma boa opção. Você diz "olha mãe hoje eu não vou comer salsicha não, salsicha é embutido, mas me faz um bife". Aí você trocou a salsicha que tem muito aditivo por bife, que não... que... se a carne for fresca, então não vai ter aditivos. Agora nós vamos aprender mais quais são os?

63. SC - Aditivos.

64. P - Quais são os aditivos, porque até agora nós só vimos um nome de um aditivo que é um nome que nós não conhecíamos, lembra-se?

65. SC - Tar... tar... tartrazino...

66. P - Corante Tartrazino. O que que é um corante, você sabe?

67. SC - Um... eu acho que é um...

Em (66) a (80) a P procura levar SC a realizar uma inferência contextual.

68. P - Uma substância, que serve pra quê?

69. SC - Dar sabor nas comidas.

70. P - Veja a palavra "corante", ela começa... 
71. SC - Com cor.

72. P - Com cor. Então são substâncias que servem pra dar?

73. SC - Cor.

74. P - Cor. Então você vê uma salsicha, que cor que tem a salsicha?

75. SC - Avermelhada.

76. P - Ela é bem vermelhinha, avermelhadinha. Então ali tem o corante pra ela ficar bem vermelhinha. Se a gente vai mascar um chiclete, abre assim, chiclete também não é colorido? Às vezes é verde, às vezes é azul... então esses são?

77. SC - Corantes.

78. P - São corantes, são aditivos. Que fazem o quê? Servem pra quê?

79. SC - Pra dar cor.

80. P - Pra dar cor. Pra que que eles querem dar cor aos alimentos? Pra que será?

81. SC - Pra dar cor...

A P está interferindo para ajudar SC a realizar a inferência, que SC atinge em (83)

82. P - Por que será que eles põem corante nos alimentos? Por que que eles fazem a salsicha ficar bem vermelhinha?

83. SC - Pra achar que é saudável.

84. P - Muito bem, então agora nós ver vamos quais são os principais aditivos. Aqui no seu livro, no seu jornal, na sua matéria, eles dividiram em três tipos... em quatro tipos de?

85. SC - Aditivos.

86. P - Então, já estão facilitando pra gente entender. Até agora nós tínhamos aprendido aditivos de modo geral, mas agora eles vão mostrar pra nós que esses aditivos podem ser classificados em?

A P leva SC a valer-se dos recursos esquemáticos do texto - no caso a listagem dos conservantes.

BORTONI-RICARDO - A leitura de livros didáticos... 
87. SC - "Conservantes".

88. P - Conservantes.

89. SC - "Corantes".

90. P - Corantes.

91. SC - "Flavorizantes - reforçadores de sabor - e adoçantes".

92. P - Muito bem, então vamos ver se a gente, antes de ler, que agora nós vamos ler quais são esses aditivos de cada tipo. Vamos ver quais que a gente já percebe pra que que ele serve. Conservantes, você acha que é pra quê?

A P está levando SC a realizar inferências contextuais.

93. SC - Conservar o alimento.

94. P - Muito bem, veja que a palavra é "conservante" porque é pra conservar, não deixar o alimento?

95. SC - Estragar.

96. P - Corantes. Nós já vimos... lembra qual palavra?

97. SC - Cor.

98. P - Cor. Então eles servem para?

99. SC - Dar cor.

100. P - Dar cor. Esse outro tipo aqui "flavorizantes" é difícil da gente saber pra que que ele serve porque essa palavra que ele lembra é uma palavra em inglês, certo? Que é "flavor", "flavor" em inglês quer dizer sabor. Eles estão usando... estão dando nome a esse grupo que reforça o sabor, mas estão usando a palavra em inglês e você ainda não estudou inglês, né? Então você não sabe. Corante é fácil, porque nós temos a palavra corante que vem de cor, conservante vem de conservar e flavorizante vem de "flavor", em inglês que a gente pronuncia /fleivor/, mas que quer dizer?

101. SC - Sabor.

102. P - Então eles usam essa palavra porque muitos desses conservantes vêm importados, são usados em outros países e alguns desses países, são países onde se fala inglês. Então, eles 
vêm com o nome de flavorizantes, porque eles pegaram esse nome por causa da palavra "flavor" que é sabor. Muito bem. Mas aqui, como o seu autor sabe que você ainda não estudou inglês, vai começar a estudar agora, mas ainda não estudou, então ele colocou aqui flavorizantes tracinho...

103. SC - "Reforçadores de sabor".

104. P - Colocou a palavra sabor, porque não dá pra gente lendo, a palavra flavorizantes, saber que é sabor. E o último que é bem fácil, que que é?

105. SC - Adoçantes.

106. P - Então, da palavra ... já dá pra gente entender, que que a gente entende... que é para?

107. SC - Adoçar.

108. P - Adoçar. Agora, então, quais são as quatro categorias, grupos de aditivos que são usados nos alimentos?

A P está promovendo uma avaliação formativa;

109. SC - "Conservantes, corantes, flavorizantes e os adoçantes".

110. P - Agora, que que nós vamos aprender? Nós vamos ver quais são esses alimentos que recebem esses aditivos. Vamos começar pelos conservantes.

111. SC - "Os mais usados nos embutidos são os nitratos que têm efeito carcinogênico, esse grupo de conservantes é usado em refrigerantes e frutas secas. Acentua os efeitos de asma em pessoas asmáticas."

SC recomeça a leitura

112. SC - "Os mais usados aditivos são os nitratos e os nitritos".

113. P - Então, esses conservantes chamados nitritos e nitratos, eles são usados em? Em que tipo de alimentos?

114. SC - Embutidos.

115. P - Então, embutidos. Eu já dei exemplos. Você vai pesquisar a palavra embutidos, mas eu já dei exemplos de alguns embutidos. Quais são? 
116. SC - Salsicha.

117. P - Salsicha, que você troca por um bifinho. Que mais?

118. SC - Lingüiça.

119. P - Lingüiça. Presunto, tá? Então, eles têm efeito carcinogênico. Muito difícil essa palavra. Vou escrever aqui. Eles provocam doenças graves como o câncer, mas você vai procurar isso aqui no dicionário. Mas além de serem carcinogênicos eles dizem que fazem mal pra quem?

120. SC - Para as pessoas asmáticas.

121. P - Você sabe o que é asma?

122. SC - É um tipo de doença.

123. P - É um tipo de doença, mas essa doença faz o quê? Não sabe? Nunca viu ninguém com asma? A asma cria dificuldades pra pessoa respirar. Vamos escrever então asma aqui? Asma. Pessoas asmáticas, que têm asma, elas têm dificuldades para puxar o ar. Felizmente que nós não temos asma. As pessoas que têm asma têm dificuldade de encher o pulmão de ar. /.../

124. P - E pra que que servem os flavorizantes?

125. SC - Pra reforçar o sabor.

126. P - Vamos ver quais são eles.

127. SC - "Entre eles está uma substância chamada glutamato monossódico, que se suspeita que seja carcinogênico embora não haja comprovação científica a respeito."

128. P - E agora ficou faltando esse último tipo, qual é o último tipo?

129. SC - Os adoçantes.

130. P - Os adoçantes. Que servem para?

131. SC - Adoçar.

132. P - Adoçar.

133. SC - "O aspartame, um adoçante artificial é utilizado em diversos produtos, como cereais, bebida light, medicamentos para crianças ou vitaminas." /.../ 
134. P - Pra que que eles põem aspartame no medicamento para crianças?

135. SC - Pra ficar com um gosto melhor.

136. P - Isso, pra ficar mais docinho, aí a criança toma, né? Então pra isso que eles põem. Agora, não está comprovado, mas suspeita-se que ele seja?

137. SC - Carcinogênico. "Alguns pesquisadores demonstraram que administração de aspartame em ratos aumenta a incidência de alguns tumores malignos, outros entendem que os resultados da pesquisa acima referida são inconclusivos e que as doses utilizadas nas experiências com ratos excedem em muito aquelas que são consumidas pelas pessoas."

138. P - Então, o que que os cientistas estão falando a respeito das pesquisas com aspartame?

139. SC - Que tem...

140. $\mathrm{P}$ - Eles fizeram pesquisas em pessoas?

141. SC - Em ratos.

142. $\mathrm{P}-\mathrm{E}$ em ratos que que o aspartame causou?

143. SC - É... doenças?

144. P - Doenças, que doenças?

145. SC - É.... tumores malignos.

146. P - Tumores malignos, como por exemplo o câncer. Então nos ratos o aspartame causou tumores malignos, mas aí o que que o autor diz pra nós? Que outros entendem o quê?

147. SC - "Que os resultados da pesquisa acima referida são inconclusivos".

148. P - Que quer dizer isso "inconclusivos"?

149. SC - Que não é certo.

150. P - Ainda não se tem uma conclusão definitiva. Eles são inconclusivos, não se tem uma conclusão definitiva. Por quê?

151. SC - "As doses utilizadas nas experiências com ratos excedem em muito aquelas que são consumidas pelas pessoas." 
Temos no episódio de leitura várias evidências de que, com o apoio dos andaimes produzidos pela $\mathrm{P}$, o SC dialogou com o texto, construindo os significados necessários à sua aprendizagem e ao seu aproveitamento na aula de Ciências. Naturalmente, o trabalho com um só aluno é bem diferente do trabalho de mediação que uma professora com várias dezenas de alunos em sala teria de realizar. No entanto, não podemos perder de vista que todo professor é, antes de tudo, um agente letrador, a quem cabe ajudar os alunos a fazer uma leitura produtiva. Várias estratégias, como os andaimes que ilustramos aqui, podem ser realizadas em sala de aula. Por exemplo, diante de um texto muito opaco, a professora pode construir um texto parafrástico de maior legibilidade, principalmente se, em sua paráfrase, ela se valer de informações presentes no universo vivencial dos alunos. Outro recurso é o de antecipar problemas para a compreensão, seja em função de um item lexical erudito ou de emprego raro nas tarefas comunicativas dos educandos, seja em função da estrutura sintática do período, como demonstram Liberato e Fulgêncio (2007). O que não se pode fazer é deixar que "o aluno se vire sozinho" para entender o seu texto didático. Essa postura omissa pode estar contribuindo para os resultados ruins do SAEB, da Prova Brasil, do PISA, do SARESP e de outros sistemas nacionais e estaduais de avaliação de leitura.

\section{CONSIDERAÇÕES FINAIS}

Concluindo, podemos dizer que a mediação do professor no processo de compreensão da leitura é um fator entre vários outros que temos de considerar quando somos confrontados com esses resultados de sistemas de avaliação. Neste trabalho, demos ênfase ao processo de andaimagem que pode ser construído pelo professor quando esse assume o papel de um agente de letramento. Tal ênfase vem ao encontro da avaliação que alunos de Ensino Médio fazem sobre os fatores mais importantes para um ensino de boa qualidade. Pesquisa com 880 jovens de escola pública, conduzida no ano em curso pela Ação Educativa (www.acaoeducativa.org.br), mostrou que os fatores mais importantes para um Ensino Médio de boa qualidade, na interpretação dos alunos, 
são "professores que dominam os conteúdos" (29\%) e "professores que sabem transmitir os conteúdos" (23\%). Entendemos que os processos de andaime, como os que ilustramos aqui, são um componente importante dessas duas categorias que os alunos elegeram como as mais relevantes para um ensino de boa qualidade.

\section{REFERÊNCIAS}

BORTONI-RICARDO, S. M. Mediando a compreensão de um livro didático de História do Brasil. In: ENDIPE: "trajetórias e processos de ensinar e aprender: práticas e didáticas", XIV. Anais do... Organizados por C. Traversini et al. Porto Alegre: EDIPUCRS, 2008. V. 2. p. 646-661.

. Compreensão de leitura: da palavra ao texto. In: GUIMARÃES, E.; MOLLICA, M. C. (Orgs.). A palavra: forma e sentido. Campinas: Pontes; RG, 2007. p. 99-107.

; SOUSA, M. A. F. Andaimes e pistas de contextualização: um estudo do processo interacional em uma sala de alfabetização. In: TACCA, M. C. (Org.). Aprendizagem e trabalho pedagógico. Campinas: Alínea, 2006. p. 167-179.

BROWN, G.; YULE, G. Discourse analysis. Cambridge: CUP, 1983.

BRUNER, J. Child's talk: learning to use language. New York: W. W. Norton, 1983.

CAZDEN, C. B. Classroom discourse: the language of teaching and learning. Portsmouth: Heinemann, 1988.

COELHO, P. C. R. O tratamento da variação lingüística no livro didático de português. 151 f. Dissertação (Mestrado em Lingüística)-Universidade de Brasília, Brasília, 2007.

DASCAL, M. Strategies of understanding. In: PARRET, H.; BOUVERESSE, J. (Orgs.). Meaning and understanding. Berlim: De Gruyter, 1981. p. 327-352.

GOFFMAN, E. A situação negligenciada. In: RIBEIRO, B. T.; GARCEZ, P. M. (Orgs.). Sociolingüística interacional. São Paulo: Edições Loyola, 2002. p. 13-20. [publicado em 1964 em American Anthropologist]

KLEIMAN, A. Texto e leitor: aspectos cognitivos da leitura. 5. ed. Campinas: Pontes, 1997. 
; MORAES, S. Leitura e interdisciplinaridade: tecendo redes nos projetos da escola. Campinas: Mercado de Letras, 1999.

LIBERATO, Y.; FULGÊNCIO, L. É possível facilitar a leitura: um guia para escrever claro. São Paulo: Contexto, 2007.

MARCUSCHI, L. A. A. Produção textual, análise de gêneros e compreensão. São Paulo: Parábola Editorial, 2008.

MULLIS, I. V. S. et alii. PIRLS: marcos teóricos y especificaciones de evaluación. Chesnut Hill, MA: Lynch School of Education; Boston College; IEA, 2006.

PEREIRA, P. V. O ato de ler: uma análise de prática da leitura em disciplinas do ensino médio. 157f. Dissertação (Mestrado em Lingüística)-Universidade de Brasília, 2007.

SAPIR, E. Lingüística como ciência. Rio de Janeiro: Acadêmica, 1969.

SOUSA, R. M. Gênero textual 'mediacional': um texto interativo e envolvente na perspectiva de um contexto específico. 143f. Dissertação (Mestrado em Lingüística)-Universidade de Brasília, 2001.

VILLAS BOAS, B. M. F. Construindo a avaliação formativa em uma escola de educação infantil e fundamental. In: . (Org.). Avaliação: políticas e práticas. Campinas, SP: Papirus, 2002. p. 113-141.

ZAMBONI, L. M. S. Cientistas, jornalistas e a divulgação científica. Campinas, SP: Autores Associados; FAPESP, 2001.

Recebido em 16/08/08. Aprovado em 23/09/08.

Title: The reading of textbooks: a neglected situation

Author: Stella Maris Bortoni-Ricardo

Abstract: Reading comprehension is a major problem in Brazilian schools. Since 1985, the Federal Government has adopted a policy of providing textbooks for every student in public schools. These textbooks are published by private publishers, but the selection of the books follows a careful government-led process. However, no attention is paid to a full understanding of these texts by the pupils. It is taken for granted that teachers will help them in this process. Our recent research has shown that indeed students may have much difficulty in comprehending their textbooks. This essay focuses on scaffolding strategies that can be used by teachers to help students develop a more efficient understanding of their textbooks.

Keywords: reading comprehension; textbook; reading strategy; scaffolding strategy. 
Titre: La lecture de livres didactiques: une situation négligée

Auteur: Stella Maris Bortoni-Ricardo

Résumé: La lecture avec compréhension est un problème crucial dans les écoles brésiliennes. Depuis 1985, le Gouvernement Fédéral a adopté une politique de distribution de livres didactiques à tous les élèves des écoles publiques. Ces livres sont publiés par des maisons d'édition privées, mais leur sélection suit un procès soigné dans le champ d'action du Ministère de l'Éducation. Cependant, les élèves à qui sont destinés ces livres leur donnent peu d'attention. On attend que n'importe quelle dificulté dans leur compréhension soit réparée en salle de classe par les professeurs. Notre recherche récente démontre qu'effectivement les élèves ont trop de difficultés dans la compréhension de ces livres didactiques. Cet essai focalise des stratégies d'échafaud que les professeurs peuvent adopter pour rendre facile aux élèves la lecture avec plus de capacité de leurs livres didactiques.

Mots-clés: compréhension de la lecture; livre didactique; stratégie de lecture; stratégie d'échafaud.

Título: La lectura de libros didácticos: una situación negligenciada

Autor: Stella Maris Bortoni-Ricardo

Resumen: La lectura con comprensión es un problema crucial en las escuelas brasileñas. Desde 1985, el Govierno Federal adoptó una política de distribución de libros didácticos a todos los alumnos de escuelas públicas. Esos libros son publicados por editoras particulares, pero su selección sigue un cuidadoso proceso en el ámbito del Ministerio de la Educación. Sin embargo, poca atención ha sido conferida a la comprensión de esos libros por los alumnos a quien ellos se destinan. Se espera que cualquier dificultad en su comprensión sea subsanada por los profesores en aula. Nuestra investigación reciente ha demostrado que de hecho los alumnos tienen mucha dificultad en la comprensión de sus libros didácticos. Este ensayo focaliza estrategias de andamio que profesores pueden adoptar para facilitar a los alumnos la lectura con más eficiencia de sus libros didácticos

Palabras-clave: comprensión lectora; libro didáctico; estrategia de lectura; estrategia de andamio.

BORTONI-RICARDO - A leitura de livros didáticos... 